\title{
When only the real thing will do: junior medical students' learning from real patients
}

Citation for published version (APA):

Bell, K., Boshuizen, E., Scherpbier, A., \& Dornan, T. (2009). When only the real thing will do: junior medical students' learning from real patients. Medical Education, 43(11), 1036-1043. https://doi.org/10.1111/j.13652923.2009.03508.x

\section{DOI:}

10.1111/j.1365-2923.2009.03508.x

Document status and date:

Published: 01/11/2009

Document Version:

Peer reviewed version

\section{Document license:}

CC BY-NC

Please check the document version of this publication:

- A submitted manuscript is the version of the article upon submission and before peer-review. There can be important differences between the submitted version and the official published version of record. People interested in the research are advised to contact the author for the final version of the publication, or visit the DOI to the publisher's website.

- The final author version and the galley proof are versions of the publication after peer review.

- The final published version features the final layout of the paper including the volume, issue and page numbers.

Link to publication

\section{General rights}

Copyright and moral rights for the publications made accessible in the public portal are retained by the authors and/or other copyright owners and it is a condition of accessing publications that users recognise and abide by the legal requirements associated with these rights.

- Users may download and print one copy of any publication from the public portal for the purpose of private study or research.

- You may not further distribute the material or use it for any profit-making activity or commercial gain

- You may freely distribute the URL identifying the publication in the public portal.

If the publication is distributed under the terms of Article 25fa of the Dutch Copyright Act, indicated by the "Taverne" license above, please follow below link for the End User Agreement:

https://www.ou.nl/taverne-agreement

Take down policy

If you believe that this document breaches copyright please contact us at:

pure-support@ou.nl

providing details and we will investigate your claim.

Downloaded from https://research.ou.nl/ on date: 26 Apr. 2023 
Bell, K., Boshuizen, H. P. A., Scherpbier, A. J. J. A., \& Dornan, T. L. (2009). When only the real thing will do: junior medical students' learning from real patients. Medical Education, 43(11), 1036-1043. doi:10.1111/j.1365-2923.2009.03508.x

\title{
When only the real thing will do: junior medical students' learning from real patients
}

\author{
Kathryn Bell,1 Henny P A Boshuizen,2 Albert Scherpbier3 \& Tim Dornan1
}

1University of Manchester Medical School, Manchester, UK

2Centre for Learning Sciences and Technologies, Open University of the Netherlands, Heerlen, The Netherlands

3Faculty of Health, Medicine and Life Sciences, Maastricht University, Maastricht, The Netherlands

\begin{abstract}
OBJECTIVES This study aimed to explore how medical students experience contacts with real patients and what they learn from them.

METHODS We carried out a post hoc, single-group study in one teaching sector of a 5-year, problembased, horizontally integrated, outcome-based and community-oriented undergraduate programme, in which students lacked clinical exposure in the pre-clerkship phase. Subjects comprised five cohorts of students on their first clerkships. Data consisted of purposively selected, voluntary, self-report statements regarding real patient learning (RPL). Constant comparative analysis was performed by two independent researchers.

RESULTS Respondents valued patients as an instructional resource that made learning more real. They reported learning through visual pattern recognition as well as through dialogue and physical examination. They more often used social than professional language to describe RPL. They reported affective outcomes including enhanced confidence, motivation, satisfaction and a sense of professional identity. They also reported cognitive outcomes including perspective, context, a temporal dimension, and an appreciation of complexity. Real patient learning helped respondents link theory learned earlier with reality as represented by verbal, visual and auditory experiences. It made learning easier, more meaningful and more focused. It helped respondents acquire complex skills and knowledge. Above all, RPL helped learners to remember subject matter. Most negative responses concerned the difficulty of acquiring appropriate experience, but RPL made a minority of respondents feel uncomfortable and incompetent.

CONCLUSIONS Real patient learning led to a rich variety of learning outcomes, of which at least some medical students showed high metacognitive awareness. Sensitivity from clinical mentors towards the positive and negative outcomes of RPL reported here could support reflective clinical learning.
\end{abstract}


Contributors: KB performed the first analysis of the data, drafted the paper, contributed to the data analysis throughout and commented on all drafts. TD supervised KB, conducted subsequent stages of analysis and finished writing the paper. HB and AS read the raw data, contributed to the data analysis and commented on all drafts. All authors gave final approval to the manuscript.

Acknowledgements: none.

Funding: none.

Conflicts of interests: none.

Ethical approval: the University of Manchester Senate Ethics Committee approved the analysis for the purposes of research of students' anonymous comments on their learning.

\section{INTRODUCTION}

Learning from real patients in clinical settings is quintessential to undergraduate medical education. Traditionally, this occurred through apprenticeship in the hospital-based provision of clinical care, which provided a tacit curriculum and a set of learning outcomes. Recent years, however, have seen important changes in health care systems and medical education. A shift in the delivery of clinical care from in-patient to ambulatory settings and from secondary to primary care has reduced opportunities for ward-based learning. Society's intolerance of threats to patient safety and the technologically sophisticated nature of care have also undermined apprenticeship. In parallel with those changes, there is a move to define explicit learning outcomes ${ }^{1}$ and to use educational methods that demonstrably achieve them, notably simulation. Although the discourse of pre-clerkship education has shifted towards learning rather than teaching, particularly in relation to early clinical exposure, ${ }^{2-4}$ clerkship education remains strongly focused on teaching. For example, just 13 research studies about real patient learning (RPL) were published in four major medical education journals during $2008,{ }^{5-17}$ of which six focused on students ${ }^{12-17}$ and only three explored learning outcomes in any depth..$^{13,15,17}$

Bleakley and Bligh recently appealed for medical education to 'get real and engage students and patients into collaborative knowledge production, where real patients represent students' text' ${ }^{18}$ But what subject matter, one might ask, does that text contain? Although many publications reviewed elsewhere ${ }^{19}$ describe clerkship experiences and how students react to them, the educational outcomes of RPL are not clearly defined. ${ }^{20}$ Four publications ${ }^{17,21-23}$ agree on some outcomes, including: an impact on students' states of mind, including their senses of professional identity and self-efficacy; development of applied knowledge, and mental models that develop through observing and interacting with qualified professionals. Otherwise, current knowledge of the outcomes of RPL is fragmentary.

We are conducting programmatic research ${ }^{24}$ to reconceptualise medical students' workplace learning. ${ }^{19,23,25-27}$ Its orientation towards communities of practice theory ${ }^{28}$ is coupled with a psychological perspective on how individuals learn from social interaction. The research is progressively refining a model of 'experience-based learning' according to which the core condition for workplace learning is supported participation, which creates conditions for RPL and results in practical learning and changes in students' states of mind. The research provides empirical support for Bleakley and Bligh's theory that RPL is located in the interaction between student and patient, wherein the clinical expert serves as facilitator.18 Our use of student self-report to identify learning outcomes is based on a theoretical stance supported by empirical evidence published elsewhere. ${ }^{25,29}$ Using this approach, we set out to establish, firstly, how medical students in the early clerkship phase report contacts with real patients and, secondly, what learning outcomes they report. The method was a post hoc, single-group quantitative and qualitative study. 


\section{METHODS}

\section{Ethical approval}

The University of Manchester Senate Ethics Committee approved the research use of students' anonymised comments about the curriculum without requesting individual participant consent.

\section{Context}

Our study context was Salford Royal Hospital, Manchester, UK, one of four teaching hospitals of the University of Manchester Medical School, where the undergraduate programme is problem-based, horizontally integrated, outcome-based and community-oriented. At the time this study was conducted, the programme offered little clinical exposure before Year 3.

\section{Subjects}

Our sampling strategy involved the purposive selection of informative data for in-depth qualitative analysis from a large representative survey. The subjects included all 521 students in Year 3 (the first year of whole-time workplace learning) of a 5-year programme during the five consecutive academic years 2001-2006. The research team comprised researchers both close to and removed from the research context, namely, a University of Manchester medical student, her supervisor (a clinician and educationalist), and two senior Dutch medical education researchers (one a cognitive psychologist and one a doctor and curriculum leader).

\section{Methodological choices and conduct}

Participants completed a web-based questionnaire four times per year, ${ }^{25,29,30}$ in which they rated various aspects of their teaching and learning using scales of 1-7, including their (dis)agreement with the statement 'I learned from real patients'. They could choose (or not) to enter free text responses to the following two items: 'Strengths of real patient learning were...' and 'Weaknesses or ways in which real patient learning could be improved...'. Responses were fed back to teachers and curriculum leaders and cumulated with anonymised metadata for curriculum quality improvement. Students were aware that the anonymised comments would be fed back to teachers and used for curriculum evaluation or research but had no direct relationship with the researchers.

\section{Analysis}

All researchers read all free text responses. Supported by NVivo 8.0 (QSR International Pty Ltd, Doncaster, Vic, Australia) and MindManager Version 8.0 (Mindjet Corp., San Francisco, CA, USA), $\mathrm{KB}$, supervised by TD, identified all free text responses in which the syntax or juxtaposition of statements had the logical structure 'A led to B' or 'B resulted from A', where A represented one or more experiences of RPL and B represented one or more learning outcomes. This selection step, combined with students' freedom not to provide free text responses, means there was no guarantee the data were theoretically comprehensive, although they were very rich. Two researchers independently coded students' textual responses and agreed a single set of codes, while the other two researchers compared successive coding schemes against the original data, helping the coders examine their biases. A second exercise aligned the thematic structure closer to the experience-based learning model and coded the data into two major categories that corresponded to the research questions:

1 How did students experience their contacts with real patients?

2 What did they learn from them?

One author wrote a narrative report, which was then compared with the original data by the other three authors, who sought text that altered or disconfirmed the interpretation. Triangulation was performed by systematically examining (dis)concordance of themes in the data and between the data and the experience- based learning model. The researchers judged the interpretation coherent and complete enough not to need more data collection (saturation). Results are reported as far as possible in the respondents' own words.

\section{RESULTS}

A total of 521 students responded to the questionnaire on 1847 of 2084 possible occasions (response rate $89 \%$ ). Their mean age was $21.5 \pm 2.2$ years (mean \pm standard deviation $[S D]$ ) and $60 \%$ were 
women. They voluntarily gave free text descriptions of the 'strengths of real patient learning' on 788 occasions (38\%) and 'weaknesses/ways real patient learning could be improved' on 285 occasions (14\%). Twenty-nine of those 285 weaknesses were negative features of RPL; the remaining 256 reported difficulties in getting enough of the right sort of RPL for organisational reasons or because patients were old, cognitively impaired, ill, in hospital transiently, over-exposed to students, shy, or suffering from disorders that were complex or irrelevant to students' current problem-based learning (PBL) case. A total of 137 positive statements qualified for qualitative analysis. All 29 'true negative' statements were included to offset any positive bias. Figure 1 shows the thematic structure of the narrative that follows.

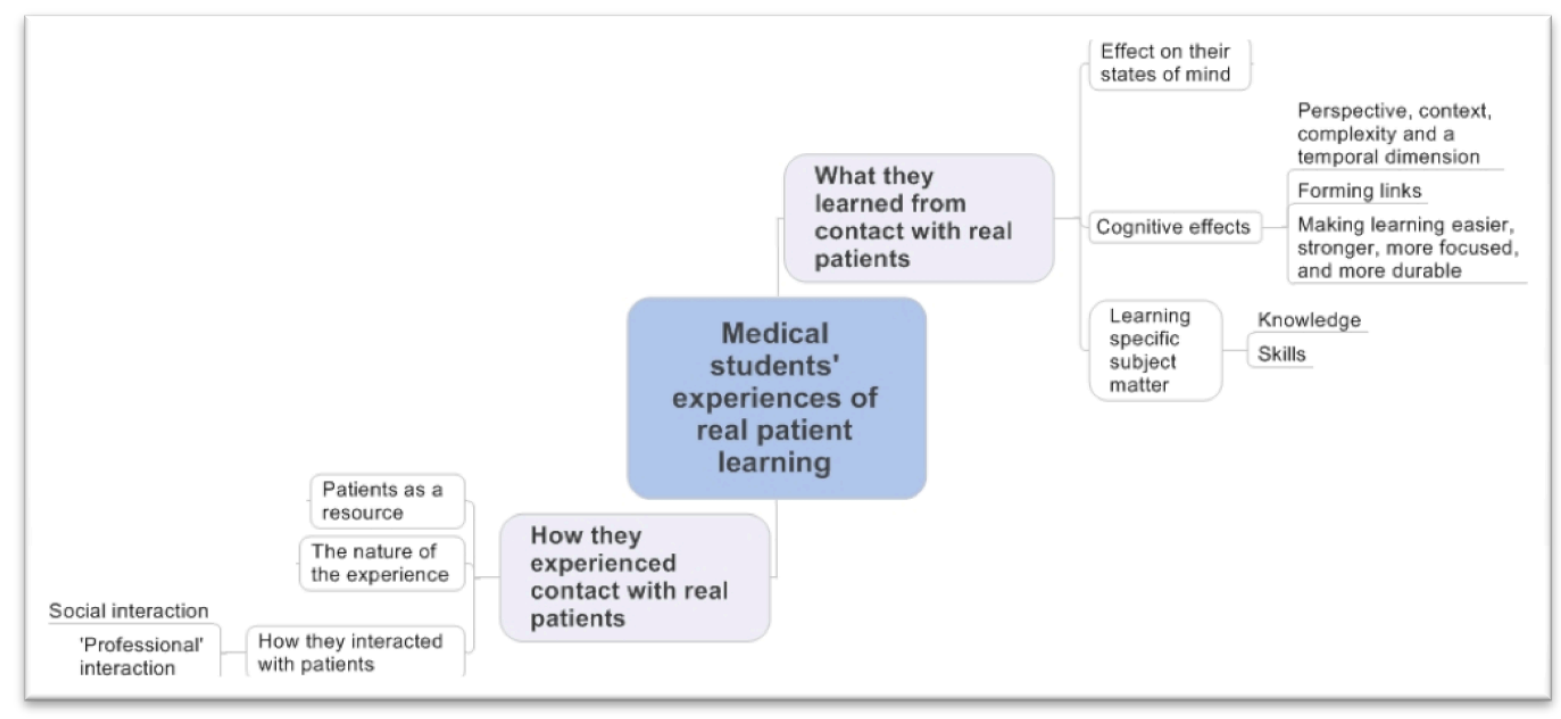

Figure 1 Thematic structure of this report

\section{How did students report their contacts with real patients?}

Patients as a resource

Forty-three responses described real patients as a valued resource. They were 'why we're here' and there could be 'no substitution' [sic] for them. 'Seeing things for real' was 'very helpful'; it gave 'a human element to the learning rather than a detached reading experience' and was unlike 'practising on a dummy'. Respondents found 'lots of patients on wards [in the] OPD [outpatient department]/in [the] community', who were 'very willing to talk freely with students'. Learning from them was immediate ('you can ask on the spot about things'), relevant, active ('the patient has often been able to explain their condition to me very well, and actually taught me a lot'), 'an eye opener' and represented a belated introduction to real patients ('seeing real patients and their illnesses at last'). Seven negative statements reported how RPL could make uncomfortable demands on students' motivation, personal organisation, initiative or confidence, and 'prevent them being taught'.

\section{Nature of the experience}

Sixty-eight responses described how learning became 'much more real' when respondents experienced instances of the 'pathologies, clinical appearances, and treatments' of 'conditions you are learning about' presented as 'patients' stories'. Respondents related 'what I am learning to a real personfface', 'visualised the signs and symptoms', 'saw multiple pathology and how pathology impacted on peoples' lives', 'saw the course of an illness' and heard 'real clinical signs'. They also experienced patients' 'personalities, descriptions and appearances'. They experienced 'clinical pictures that were a little more unusual' and 'memorable patients'. They experienced 'good examples of multipathologies', symptoms 'occurring together', 'patients in different settings' and 'the whole picture'.

How students interacted with real patients

Social interaction. Twenty-six responses described real patient interaction in the language of social interaction, for example: 'meeting patients'; 'interacting with the patient'; 'talking to patients'; 
'speaking in depth with them'; 'getting to know a patient'; 'patients give you the invaluable first-hand views'; 'the patient has been able to explain their condition to me', and 'it is fun to hear about people's lives'.

Professional interaction. Fourteen responses (four of which also used social language) were expressed in the language of professional interaction: 'being able to take histories and examine patients on the wards '; learning 'practicalities by examining and talking to real patients', and 'I could clerk the patients in, the house officers were keen to teach about patient management and best of all presenting on the ward round was an excellent experience'.

\section{What learning did students report?}

\section{Effect on respondents' states of mind}

Twenty-two statements described how contact with real patients helped build and sustain a positive state of mind. It helped 'overcome anxieties at meeting real patients', increased 'confidence about one's own capabilities', which included 'talking to patients and taking a more detailed history' and 'picking up clinical signs'. It made respondents 'more enthusiastic to learn' and 'maintained enthusiasm when having a bad day'. It motivated respondents to study theory. For two of them, 'the inability to take a pertinent history or accurately diagnose what the patient was suffering from' and 'not understanding their symptoms and not being able to alleviate their illness or suffering' was 'the main stimulus behind that impetus'. Positive emotions were expressed in words such as 'excellent', 'fun', 'interesting', 'enjoyable' and 'exciting', and one respondent found social contact with patients 'served as a welcome break'. Real patient contact made one respondent 'finally feel as if I was on the path towards becoming a doctor'. On the negative side, 16 statements described how RPL made respondents feel confused, ill prepared for assessments, unconfident, scared, 'like a lost soul', in the way, or concerned they would become emotionally overinvolved. Some respondents were concerned they were invading patients' privacy, patients did not understand why they were there, or patients did not want to speak to them.

\section{Cognitive effects}

Perspective, context, complexity and a temporal dimension. Thirteen responses described how seeing real patients gave a 'different perspective', which included 'a view from the other side' and 'a psychological perspective, which books lack'. It was 'good to be exposed to the holistic approach', which showed respondents there was 'more to a disease than a pathological process'. For four respondents, 'seeing real patients and their illnesses helped put into context the last 3 years of looking in a textbook'. Four respondents noted the complexity of clinical experience, which 'gave insight into the multi-layered nature of most patients' problems', and three noted they could 'see the course of an illness' and understand its variability. On the negative side, one respondent described how RPL made the student feel unclear about his or her intended learning outcomes.

Forming links. Fourteen responses described how 'seeing patients brought things you'd read about a certain condition together' and how 'seeing the course of an illness and hearing patients' accounts of diseases fixed in my mind what I had read in books'. For one respondent, 'linking is demonstrated very nicely when a doctor talks you through how they've arrived at a diagnosis'.

Making learning easier, stronger, more focused and more durable. Twenty-eight responses told how 'seeing signs and symptoms in real patients was the strongest reinforcement' of learning. It 'made information easier to learn', 'helped solidify and consolidate knowledge', 'focused the mind on learning (compared with falling asleep with a book)', and increased the amount that was learned. For two respondents, real patients were 'THE ONLY WAY TO REALLY KNOW YOUR STUFF!!' [sic]. The commonest single effect of real patient contact, expressed in 74 statements, was that it helped respondents remember subject matter: almost every such response stated or implied 'the patient sticks in your mind, so when you think of a disease, it is linked to that patient in your mind'. Likewise, signs and symptoms were 'made memorable' by 'taking histories and [conducting] examinations'.

Encountering 'medicine in action, rather than medicine in theory, made theory more memorable'. The phrase 'it's easier to remember a face than words' captured the visual impact of patients on respondents' memories.

\section{Learning specific subject matter}

Knowledge. Fifteen responses concerned theoretical knowledge; for example, 'dry science from preclinical' was 'much more understandable now it relates to a real person with real concerns'. In 19 
responses, the subject matter was common patterns of health and disease; in two it was patients 'not being textbook in terms of their presentations'; in four it was clinical management, and in six it was 'things you can't learn from books that you have to experience from patients'. Twenty-one responses concerned the 'impact of disease on a person's life, the effect it has on their family and their concerns about their health and their future', 'how they deal with it', 'how they feel and why they feel that way', and 'why people who are ill behave the way they do and how I could help'.

Skills. Eighteen responses described how 'being forced to constantly assess how you relate to people' taught communication, the skill of 'talking to every kind of person'. Two described empathic understanding as 'an approach to the patient in terms of being more understanding and sympathetic'. Five described how real patients 'improved my history-taking skills' 'because they are not like the SP [simulated patient] we get in communication skills'. Four described learning 'examination skills' and one described 'learning a clinical procedure'. Three described developing diagnostic skills: 'You start to build up pattern recognition right from the first day'; 'I have seen a patient who is jaundiced so I will be able to distinguish it in the future', and 'a clinical picture that's a little more unusual makes you think of other differentials'. Six responses emphasised the integrative nature of learning the skills of a good doctor, expressed by one respondent as:

'If you want to be a doctor then the only true way to become a good one is to practise on lots of patients. Not just to practise history taking, examinations and skills, but also to ask the patients about their diseases and problems and how they affect them. If you associate a disease and its signs and symptoms with a patient that you examined, then you will remember it forever.'

On the negative side, RPL made five respondents feel incompetent, particularly when they had to apply clinical skills or interpret abnormal signs without a teacher's help.

\section{DISCUSSION}

The large number of voluntary, positive textual responses from students in the first whole-time clerkship year of a problem-based but non-vertically integrated programme indicated that learning from patients was valuable just because it was real. Respondents described how they apprehended reality by hearing what patients had to say, seeing them, touching them and hearing audible physical signs. They more often used social than professional language to describe such interactions. They said RPL supported affective learning, by which we mean the process of becoming more confident, motivated and satisfied, and developing a sense of professional identity. It gave perspective, context and a temporal dimension, and located learning within the complexity of reality. It formed links between theory learned earlier and reality as apprehended through verbal, visual and auditory cues. It made learning easier, stronger and more focused. It helped respondents to learn subject matter that could not be presented in any other ways and to acquire complex skills such as making diagnoses. Above all, students said RPL helped them to remember subject matter. Most negative comments indirectly supported the value of RPL because they were complaints about the difficulty of acquiring RPL, but a vocal minority of respondents indicated that their state of mind had been adversely affected by RPL.

The importance of our study is four-fold. Firstly, it endorses the value of RPL. ${ }^{22,31}$ This is not to deny the importance of PBL and simulation education, but to emphasise that RPL provides complementary benefits and can help learners transfer what they learn from simulation to reality. Secondly, the study provides an inventory of learning outcomes, although the finding that experiencing reality is intrinsically worthwhile is rather at odds with the basic principles of outcome-based education. The similarity between this set of learning outcomes and our previously published inventory of benefits of RPL in the preclerkship phase ${ }^{2}$ is striking, endorsing the view of one of our respondents that Year 3 was rather late to be introducing RPL. Thirdly, it is salutary that students used the language of social interaction to describe how RPL enriched their cognitive processes, whereas a previous survey found their teachers mostly framed interaction with patients in terms of 'clerking them' ${ }^{32}$ Bleakley and Bligh foresaw this finding when they wrote of medical education refusing the deliberate use of patients as a primary source for learning. ${ }^{18}$ Fourthly, it was not just what students said, but the fact that they said it that was important. Medical students at the University of Manchester are not routinely taught the cognitive psychology of learning, yet it was clearly visible in their accounts of cognitive restructuring, linking, strengthening knowledge, pattern recognition and apprehension of learning through all the senses. We suggest that these statements indicated a high level of metacognition ${ }^{33}$ ("knowing about your knowing') amongst at least some respondents. Bleakley and Bligh proposed that RPL might promote the formation of tacit knowledge (scripts, pattern recognition and encapsulated knowledge) 
and provide a foundation for professional expertise. Certainly, teachers could promote reflective learning and expertise development by drawing on students' metacognitive insights into their learning in mentorship discussions.

Strengths of the study included its $89 \%$ overall response rate and $40 \%$ voluntary textual response rate, as well as a rigorously performed qualitative analysis. Nevertheless, the study had limitations. The textual data consisted of self-reports, the subjectivity of which bedevils qualitative research because the text a researcher analyses is the text a respondent has chosen to give her. Given that there was no obligation to provide free text at all, anonymity was maintained and responses were given primarily for programme evaluation rather than research purposes, these qualitative data may be more trustworthy than some. Our impersonal method of obtaining qualitative data allowed participants to respond anonymously and voluntarily. However, it lacked the exploratory power of focus groups or interviews and gave no encouragement to reticent students to participate. Responses were fragmentary and therefore analysing them relied more on the research team's interpretation of them than would be the case with more fluent and complete textual responses. That said, the researchers did not find it hard to analyse the data, perhaps because medical students are well educated and accustomed to expressing important matters in few words. Moreover, we only analysed the $20 \%$ of positive responses that had an 'A leads to B' logic so that we could infer causal links between the experiences and outcomes of RPL.

Students who respond negatively to RPL are an important group for further study, which should test if their negative responses are consistent and whether they correlate with other measures of progression through and beyond the undergraduate programme. Exposure to real patients is an experience that tests students' sense of vocation and identity and thus an adverse reaction to RPL in the early phase of a programme may mark out those who are not well suited to a clinical career. It would be valuable, also, to see if students' reactions to RPL are similar later in the programme or whether our findings reflect students' relatively recent entry to the clinical environment. It would be valuable to test empirically, perhaps using an action research design, whether the insights reported here can be capitalised upon in mentoring medical students. Finally, the value of making the benefits of RPL as defined in this study explicit in an outcome-based curriculum is worthy of study.

We conclude that RPL leads to a rich variety of learning outcomes, which we have inventoried. However, we are agnostic about the value of representing them in an explicit outcome-based curriculum, at least pending further study. Nonetheless, the fact that at least some students are very aware of how they learn from real patients suggests clinical mentors might usefully draw out and build upon those insights.

\section{REFERENCES}

1 Harden RM. Outcome-based education: the future is today. Med Teach 2007;29:625-9.

2 Dornan T, Littlewood S, Margolis S, Scherpbier A, Spencer J, Ypinazar V. How can experience in clinical and community settings contribute to early medical education? A BEME systematic review. Med Teach 2006;28:3-18.

3 Dyrbye LN, Harris I, Rohren CH. Early clinical experiences from students' perspectives: a qualitative study of narratives. Acad Med 2007;82:979-88.

4 Diemers AD, Dolmans DH, van Santen M, van Luijk SJ, Janssen-Noordman AM, Scherpbier AJ. Students' perceptions of early patient encounters in a PBL curriculum: a first evaluation of the Maastricht experience. Med Teach 2007;29:135-42.

5 Quaintance JL, Arnold L, Thompson GS. Development of an instrument to measure the climate of professionalism in a clinical teaching environment. Acad Med 2008;83 (Suppl):5-8.

6 Leong SL, Lewis PR, Curry WJ, Gingrich DL. Tobacco World: evaluation of a tobacco cessation training programme for third-year medical students. Acad Med 2008;83 (Suppl):25-8.

7 Graffam B, Bowers L, Keene K. Using observations of clinicians' teaching practices to build a model of clinical instruction. Acad Med 2008;83:768-74.

8 Williams KN, Ramani S, Fraser B, Orlander J. Improving bedside teaching: findings from a focus group study of learners. Acad Med 2008;83:257-64.

9 Hatala R, Issenberg SB, Kassen B, Cole G, Bacchus CM, Scalese RJ. Assessing cardiac physical examination skills using simulation technology and real patients: a comparison study. Med Educ 2008;42:628-36.

10 Passaperuma K, Higgins J, Power S, Taylor T. Do patients' comfort levels and attitudes regarding medical student involvement vary across specialties. Med Teach 2008;30:48-54. 
11 Haffling A-C, Hakansson A. Patients consulting with students in general practice: survey of patients' satisfaction and their role in teaching. Med Teach 2008;30:622-9.

12 de Wever B, van Winckel M, Valcke M. Discussing patient management online: the impact of roles on knowledge construction for students interning at the paediatric ward. Adv Health Sci Educ Theory Pract 2008;13:25-42.

13 Knight LV, Rees CE. 'Enough is enough, I don't want any audience': exploring medical students' explanations of consent-related behaviours. Adv Health Sci Educ Theory Pract 2008;13:40726.

14 Ottenheijm RPG, Zwietering PJ, Scherpbier AJJA, Metsemakers JFM. Early student-patient contacts in general practice: an approach based on educational principles. Med Teach 2008;30:802-8.

15 Wu EH, Elnicki DM, Alper EJ et al. Procedural and interpretive skills of medical students: experiences and attitudes of fourth-year students. Acad Med 2008;83 (Suppl):63-7.

16 Mihalynuk T, Bates J, Page G, Fraser J. Student learning experiences in a longitudinal clerkship programme. Med Educ 2008;42:729-32.

17 Martinez W, Lo B. Medical students' experiences with medical errors: an analysis of medical student essays. Med Educ 2008;42:733-41.

18 Bleakley A, Bligh J. Students learning from patients: let's get real in medical education. $A d v$ Health Sci Educ Theory Pract 2008;13:89-107.

19 Dornan TL. Experience-based Learning. Learning Clinical Medicine in Workplaces. PhD thesis Maastricht University. 2006.

20 Bordage G, Burack JH, Irby DM, Stritter FT. Education in ambulatory settings: developing valid measures of educational outcomes, and other research priorities. Acad Med 1998;73:743-50.

21 Fernald DH, Staudenmaier AC, Tressler CJ, Main DS, O’Brien-Gonzales A, Barley GE. Student perspectives on primary care preceptorships: enhancing the medical student preceptorship learning environment. Teach Learn Med 2001;13:13-20.

22 Ratanawongsa N, Teherani A, Hauer KE. Third-year medical students' experiences with dying patients during the internal medicine clerkship: a qualitative study of the informal curriculum. Acad Med 2005;80:641-7.

23 Dornan T, Boshuizen H, King N, Scherpbier A. Experience-based learning: a model linking the processes and outcomes of medical students' workplace learning. Med Educ 2007;41:84-91.

24 Bordage G. Moving the field forward: going beyond quantitative-qualitative. Acad Med 2007;82 (Suppl):126-8.

25 Dornan T, Muijtjens A, Hadfield J, Scherpbier A, Boshuizen H. Student evaluation of the clinical 'curriculum in action'. Med Educ 2006;40:667-74.

26 Ashley P, Rhodes N, Sari-Kouzel H, Mukherjee A, Dornan T. They've all got to learn. Medical students' learning from patients in ambulatory consultations. Med Teach 2009;31:e24-e31.

27 Dornan T, Scherpbier A, Boshuizen H. Supporting medical students' workplace learning: experience-based learning (ExBL). The Clinical Teacher 2009;6:167-71.

28 Lave J, Wenger E. Situated Learning. Legitimate Peripheral Participation. Cambridge: Cambridge University Press 1991.

29 Dornan T, Boshuizen H, Cordingley L, Hider S, Hadfield J, Scherpbier A. Evaluation of selfdirected clinical education: validation of an instrument. Med Educ 2004;38:670-8.

30 Dornan T, Scherpbier A, Boshuizen H. Towards valid measures of self-directed clinical learning. Med Educ 2003;37:983-91.

31 McGrew MC, Skipper B, Palley T, Kaufman A. Student and faculty perceptions of problembased learning on a family medicine clerkship. Fam Med 1999;31:171-6.

32 Dornan T, Scherpbier A, King N, Boshuizen H. Clinical teachers and problem-based learning: a phenomenological study. Med Educ 2005;39:163-70.

33 Meijer J, Veenman MVJ, van Hout-Wolters BHAM. Metacognitive activities in text-studying and problem-solving: development of a taxonomy. Educ Res Eval 2006;12:209-37. 